\title{
On the Series
}

Ever since the 1990s, "globalization" has been a dominant idea and, indeed, ideology. The metanarratives of Cold War victory by the West, the expansion of the market economy, and the boost in productivity through internationalization, digitization and the increasing dominance of the finance industry became associated with the promise of a global trickle-down effect that would lead to greater prosperity for ever more people worldwide. Any criticism of this viewpoint was countered with the argument that there was no alternative; globalization was too powerful and thus irreversible. Today, the ideology of "globalization" meets with growing scepticism. An era of exaggerated optimism for global integration has been replaced by an era of doubt and a quest for a return to particularistic sovereignty. However, processes of global integration have not dissipated and the rejection of "globalization" as ideology has not diminished the need to make sense both of the actually existing high level of interdependence and the ideology that gave meaning and justification to it.

The following three dialectics of the global are in the focus of this series:

Multiplicity and Co-Presence: "Globalization" is neither a natural occurrence nor a singular process; on the contrary, there are competing projects of globalization, which must be explained in their own right and compared in order to examine their layering and their interactive composition.

Integration and Fragmentation: Global processes result in de- as well as reterritorialization. They go hand in hand with the dissolution of boundaries, while also producing a respatialization of the world.

Universalism and Particularism: Globalization projects are justified and legitimized through universal claims of validity; however, at the same time they reflect the worldview and/or interests of particular actors. 

Dedicated to the memory of Yeh Wu Su-Zhu 葉吳素珠 
